Voix et Images

voixetimages

\title{
Les passeurs de récit
}

\section{Lucie Robert}

Volume 28, numéro 3 (84), printemps 2003

Gilles Cyr

URI : https://id.erudit.org/iderudit/006763ar

DOI : https://doi.org/10.7202/006763ar

Aller au sommaire du numéro

\section{Éditeur(s)}

Université du Québec à Montréal

\section{ISSN}

0318-9201 (imprimé)

1705-933X (numérique)

Découvrir la revue

Citer ce compte rendu

Robert, L. (2003). Compte rendu de [Les passeurs de récit]. Voix et Images, 28(3), 163-170. https://doi.org/10.7202/006763ar services d'Érudit (y compris la reproduction) est assujettie à sa politique d'utilisation que vous pouvez consulter en ligne.

https://apropos.erudit.org/fr/usagers/politique-dutilisation/ 


\section{Dramaturgie}

\section{Les passeurs de récit}

\section{Lucie Robert, Université du Québec à Montréal}

La liberté narrative revendiquée par les auteurs dramatiques contemporains engendre, outre l'abandon de l'action dramatique classique, ce que Jean-Pierre Ryngaert nomme une "dramaturgie de l'émiettement", c'està-dire "une pratique du fragment qui relève de l'abandon du point de vue et finalement de l'impossibilité d'accéder à toute vision ordonnée ${ }^{1}$ ". Monologues successifs, parallèles ou croisés, meublent alors l'espace scénique, où les personnages se rencontrent de manière fugitive ou, parfois même, se succèdent sans jamais se rencontrer. La nécessité demeure néanmoins de créer une forme d'unité, qui donne au texte dramatique ses frontières, mais aussi son centre, et les auteurs réunissent le plus souvent ces fragments autour d'un événement fédérateur, dont il appartiendra au lecteur ou au spectateur de saisir les enjeux et le sens.

Il me semble cependant que les auteurs dramatiques ont développé ces dernières années une nouvelle manière de créer une telle unité. À côté de cet événement, que la pièce peut déployer selon des points de vue multiples, se trouve également un personnage nouveau, lui-même fédérateur d'une série d'événements, de points de vue, voire de récits multiples, un personnage qui, d'une certaine manière, absorbe le monde et s'en nourrit. Se crée ainsi une structure de médiation où le personnage principal, destinataire du récit des autres personnages, agit comme un passeur de récits, situé entre les personnages secondaires et le public, dans un échange conçu non plus comme un conflit entre deux subjectivités, mais comme une opération de transmission et donc de mémoire. Rien n'illustre mieux cette structure que la dramaturgie de Carole Fréchette où Marie, Élisa et Simon Labrosse déjà s'imbibaient des récits d'autrui, avalant les bruits de la Cité, pour se maintenir en vie ${ }^{2}$. En 2002, Carole Fréchette publie trois nouvelles pièces fondées sur cette forme singulière, mais proposant chacune un enjeu différent.

Créée le 24 janvier 2002 à Sudbury et reprise le 12 mars 2002 à l'Hippodrome de Douai (France), dans une mise en scène de Vincent Goethals, assisté d'André Perrier, Violette sur la terre ${ }^{3}$ a été écrite à la demande du Théâtre du NouvelOntario, du Théâtre de Tandem et du Théâtre en Scène, qui cherchaient "une pièce inspirée par l'univers des mines" (p. 7). Nous sommes donc dans une région singulière, mais jamais nommée, dont le tissu social s'est peu à peu désagrégé. Les personnages sont désorientés. Leur monde s'effondre et ils ne savent comment réagir. Quatre de ces personnages se retrouvent par hasard au milieu de nulle part (le milieu de nulle part paraît bien caractériser cet 
univers). Paul a jadis subi un grave accident. Étienne, le syndicaliste révolté, tourne en rond, n'ayant d'autre perspective que de collectionner les bâtons de dynamite en espérant tout faire sauter. Marie-Jeanne, sa femme, n'en peut plus. Étienne et elle ne se sont pas adressé la parole depuis presque six mois; elle est seule et sans enfant, coincée dans une relation d'où le désir et l'amour ont disparu. Judith hésite à avoir un enfant d'Éric puisque ce serait se mouler à une vie écrite d'avance dans un lieu où il ne se passe plus rien.

Seuls d'abord, puis ensemble, ces quatre personnages ont rencontré par hasard une femme, qui reste là sans parler. Chacun est amené à interpréter les silences de Violette, puis à les meubler de ses propres histoires. Paul écrit dans son carnet; il prend des notes, copie des chansons qu'il offre maintenant à Violette: "J'ai pensé à ça toute la journée. À vous apporter les paroles." (p. 17) Judith apporte des gâteaux, Marie-Jeanne, ses histoires, Étienne, sa révolte, mais aussi son petit papier, une liste des "aberrations du monde" (p. 15). Mais qui est Violette? Le personnage apparaît comme une énigme. Elle aussi a un carnet, que Judith a découvert en fouillant dans le sac, un carnet plein de phrases raturées, sauf la dernière, restée intacte: "Je me suis trompée." (p. 34) Violette précisera: "Je me suis trompée de route, de projets, d'amour, de vie." (p. 61) Elle apparaît ainsi comme le miroir du monde, d'un monde qui s'est effacé devant, sous ou derrière elle, comme celui des autres personnages. Autour d'elle, ceux-ci réapprennent à parler, à dire leur peur, à s'aider peut-être. Mais voilà que le vent se lève et qu'une tempête de sable s'annonce. Il faut trouver un refuge et le seul lieu disponible est celui où Étienne cache sa dynamite. Violette n'est plus là.

D'une certaine manière, le personnage de Violette, qui se nourrit des histoires qu'on lui raconte, ressemble à l'auteure qui se met à l'écoute d'un milieu singulier, chaque fois déterminé par la logique du théâtre de commande. Il faudra un jour savoir gré à Fréchette d'avoir renouvelé ce genre si didactique, en évitant de nous assommer de thèses déjà pensées et en le concevant d'abord comme un instrument de transmission et de mémoire. Elle y revient dans Le collier d'Hélène ${ }^{4}$, pièce créée le 19 avril 2002 au Théâtre Sama de Damas et le 23 avril au Théâtre de Beyrouth. Au coin d'une rue, à une intersection achalandée, Hélène cherche un collier qu'elle a perdu et elle finit par prendre un taxi vers le centre de la ville, n'importe où. Elle s'arrête d'abord près d'un chantier de construction avec "Des poutres et du béton. Comme un squelette de bâtiment. Avec des grues. Des grues, vous voyez. Des machines avec un long cou et..." (p. 10) Le contremaître l'éconduit: "régulièrement, je vois des gens comme vous qui viennent chercher une chose qu'ils ont perdue" (p. 13). Il a lui-même perdu sa maison, détruite par une bombe. Puis le taxi la mène dans une petite rue, où une femme cherche la balle rouge de son fils. On apprendra que ce fils a été tué dans une embuscade et que, depuis ce jour, tous les lundis, la mère reprend sa quête. De nouveau le taxi, puis la rencontre d'un homme 
qu'elle croit reconnaître et qui lui fait promettre de crier de temps à autre: lui qui a toujours vécu dans un camp sait qu'on ne peut plus vivre en silence. Encore le taxi, qui va vers la mer où un rôdeur veut lui vendre un autre collier. Peu à peu, Hélène comprend la remarque du chauffeur: "Les choses nous quittent, Hélène, il faut l'accepter [...] Il vous reste beaucoup de choses." (p. 43) On le voit, non content d'absorber les récits d'une humanité malmenée, le personnage de Fréchette, qu'il ait nom Marie, Élisa, Simon, Violette ou Hélène se révèle lui-même aux prises avec une identité incertaine, en quête d'une existence qui lui serait propre: "Est-ce que vous vous êtes déjà inventé une histoire tragique parce que votre petit malheur vous semblait indécent?" (p. 37)

C'est exactement ce que fait Béatrice qui s'imbibe elle aussi du discours d'autrui pour vivre, mais qui, plutôt que de se mettre à l'écoute des autres, commande le discours et impose sa logique propre. Créée au Théâtre d'Aujourd'hui le 12 mars 2002, dans une mise en scène de Maurice Garcia Lozano, assisté de Jean Béllanger, Jean et Béatrice ${ }^{5}$ se passe dans "une grande pièce presque vide" (p. 7), située au 33e étage d'un immeuble. Jean, un chasseur de primes, est venu en réponse à une petite annonce placée par Béatrice: "Avis aux hommes de cette ville. Jeune héritière, lucide et intelligente, qui n'a jamais aimé personne, ni sa mère, ni son père, ni son chat, ni sa tante des États [...], ni sa bonne Jeannine [...], ni les quatorze amants qu'elle a eus en quatorze ans de vie sexuelle, recherche un homme qui pourra l'intéresser, l'émouvoir et la séduire. Dans l'ordre. Récompense substantielle." (p. 9-10) La jeune femme prétend être la fille d'un "magnat de la poubelle en plastique" qui, à sa mort, lui aurait légué une immense fortune. Jean n'est pas le premier à répondre à l'annonce, mais Béatrice a renvoyé tous les autres, "la plupart avant même que ça commence" (p. 14). Il y aura trois épreuves : à la première, Jean doit "raconter une histoire qui me captive totalement" (p. 17); à la seconde, il doit émouvoir Béatrice jusqu'aux larmes et, à la troisième, la séduire. Jean sort victorieux des trois épreuves, mais c'est pour découvrir que Béatrice lui a menti et qu'elle n'a à lui offrir, en guise de rétribution, que des histoires: "Voulez-vous une histoire?" (p. 47). Non, répond Jean: "je veux quelque chose de concret". Soit. Au deuxième acte, Béatrice a fermé la porte et jeté la clef par la fenêtre: "Maintenant on est enfermés ici et... on s'aime." (p. 52) Les deux personnages entreprennent alors une sorte de pas de deux, formé des gestes et des paroles propres au rituel amoureux, mais vides de sens: raconter sa vie, se gratter le dos réciproquement, dormir côte à côte, se disputer, se réconcilier. Là est le seul "concret" que Béatrice puisse offrir, mais l'on demande si par là elle ne réussira pas finalement à convaincre Jean de rester.

$$
* *
$$

On a, jusqu'à maintenant, rarement noté la parenté entre le travail dramaturgique de Wajdi Mouawad et celui de Carole Fréchette. Chez l'un comme chez l'autre, le personnage du passeur de récits rappelle la 
dramaturgie de Luigi Pirandello. Car tous ces personnages arrivent avec leur histoire propre que le dramaturge doit structurer en une action cohérente. Mais là où l'écrivain italien montrait la relativité des points de vue et l'incapacité des personnages seuls à concevoir une histoire unifiée, le passeur de récits se désigne lui-même comme un point de focalisation qui reçoit ces points de vue sans les unifier. La plus récente pièce de Mouawad, Rêves ${ }^{6}$, surgit du même type d'interrogation que celles de Fréchette: "En quoi la création at-elle un lien avec le monde? Comment vivre dans l'écriture lorsqu'on en a été arraché?» (p. 6)

Créée le 3 juin 1999 à l'Agora de la danse de Montréal, dans le cadre du Festival de théâtre des Amériques, dans une mise en scène de l'auteur, assisté de Lucie Janvier, reprise en France le 23 septembre 2000 au Théâtre de l'Union, dans le cadre du Festival international des francophonies du Limousin, Rêves se passe dans une chambre d'hôtel. L'incipit est donné par la voix de la Femme emmurée: "Est-ce que quelqu'un m'entend?" (p. 11), mais l'action commence quand le personnage principal, Willem, arrive dans un hôtel à peu près vide où rien n'est prêt à recevoir les visiteurs ("c'est pas la saison ", explique l'Hôtelière [p. 11]). Ayant sorti un grand cahier noir, Willem s'adresse à Isidore, un personnage qui vient d'entrer dans la chambre: "Il y a maintenant quelque temps, tu m'as envoyé un personnage." (p. 16) Il s'agit d'"un homme qui marchait pour aller vers la mer" (p. 17). De ce personnage, Willem prévoit écrire un roman, mais il ne sait rien d'autre: "pas d'histoire, pas d'action, rien, un homme qui marche et son monologue intérieur qui le structure" (p. 18). Par la suite, on apprendra que l'Hôtelière a un fils, installé en Amérique du Sud, que ce fils aussi écrit "toujours la même histoire" (p. 22), celle de "l'Aurican qui un jour arrêta l'Inca Tupac Yupanki à la limite du Bio Bio qui s'écoule depuis le haut de la cordillère des Andes" (p. 22).

Nous avons donc une structure symétrique, où deux hommes sont habités par un personnage dont ils tentent de raconter l'histoire. D'autres personnages interviennent: l'Homme écroulé, la Femme décharnée, la Femme immobile, l'Homme ensanglanté, la Femme décapitée, l'Homme abîmé, la Femme ensevelie, l'Homme silencieux, l'Homme en larmes, comme autant de tentatives de faire surgir le récit de celui qui marchait vers la mer. Survient, l'Aurican, inquiet: "Je n'entends plus mon auteur. Je ne le vois plus, je ne me sens plus appelé par son inspiration." (p. 43) À ce moment même, le destin de l'Hôtelière bascule: par téléphone, elle apprend la mort de son fils. La nuit terminée, Willem reprend son chemin, mais ce n'est pas sans avoir permis à l'Hôtelière de retrouver son souvenir, celui d'une représentation de ballet qui l'avait bouleversée autrefois. Ayant ainsi compris le pouvoir salvateur de la création, elle s'assoit avec les cahiers de son fils, puis danse avec l'Aurican.

$$
\text { ** }
$$

Pièce écrite à quatre mains, par Myriam Houle et Marie-José Normand, Les soifs du désert ${ }^{7}$ a été créée à la salle intime du théâtre Prospéro 
à Montréal le 17 avril 2001, dans une mise en scène de Frédéric Dubois. Aux trois personnages, la Tante, la Jumelle et la Sour, correspondent trois espaces scéniques distincts, mais un seul lieu fictif: un gratte-ciel dans un désert. La Tante se pose d'emblée comme écrivaine: "Je suis auteure, j'invente des histoires, je suis une écrivaine en fuite." (p. 11) Vingt ans plus tôt, en effet, elle s'est enfuie avec les jumelles dont sa sour venait d'accoucher: "J'humai leur odeur de nouvelle vie et me mis à courir [...] $\mathrm{Au}$ bout de trois jours, je me suis reposée. Je me suis arrêtée ici... au beau milieu de ce désert." (p. 13) Depuis, ce sont les jumelles qui inventent les mots de la tante. Mais voici qu'au vingtième anniversaire, plus rien ne va. Les jumelles refusent de continuer à jouer les muses. L'une regarde au-delà du désert, cherchant à meubler sa vie propre. L'autre découvre dans le dictionnaire un objet particulier qu'elle désire plus que tout: l'homme. La Tante résiste, mais elle ne peut que s'incliner: "Comme j'ai été naïve de croire que tout ça n'aurait pas de fin. Voilà vingt ans que j'écris, guidée par des muses, mes muses. Et je vois mon œuvre s'achever car les mots ont besoin de s'incarner." (p. 51)

À mesure que la nouvelle réalité s'impose, les mots de la fiction construite par la tante s'effacent. Par le regard de l'Homme, une des jumelles comprend peu à peu qu'elle n'existe pas, qu'elle est morte depuis vingt ans et doit d'abord aux récits de la Tante et à la parole le fait d'avoir survécu, sinon de corps, du moins dans le rêve et dans l'imagination. C'est donc sa sour qui partira avec l'Homme, libérée de l'imaginaire pour rejoindre le réel, sortant du désert pour retrouver le monde, s'incarnant enfin dans un corps de femme. Après la libération de ses muses, la Tante n'a d'autre choix que celui de se remettre à écrire: "Je suis un assassin. Laissez-moi vous parler de moi..." (p. 121) La venue de l'Homme n'est pas sans rappeler l'aventure du Petit prince de SaintExupéry, d'ailleurs cité comme un hypotexte avoué.

\section{***}

"Si vous en éprouvez le désir, je voudrais vous léguer ma mémoire. Toute ma mémoire. Mes souvenirs de chair et ceux qui brillent dans le caveau [...] Emplissez votre cour [...] Mangez gras, faites des études inutiles et adressez la parole aux étrangers." (p. 78-79) Telles sont les paroles qui forment le testament de Sacha dans Le goûteur ${ }^{8}$ de Geneviève Billette, pièce créée le 5 mars 2002 à l'Espace Go dans une mise en scène de Claude Poissant. Depuis la mort d'Octavie, le grand amour de sa vie qu'il espère rejoindre bientôt, Sacha s'est institué comme la mémoire de l'entreprise et comme le tuteur de Nils, le fils d'Octavie. Or, Nils a un pouvoir particulier: il goûte, c'est-à-dire qu'il a "la papille absolue" (p. 26) comme d'autres ont une oreille absolue. Aussi Sacha convainc-il Nils d'entrer au service de l'entreprise, espérant par là, d'une part, rappeler à Sheila, l'actuelle présidente, la mémoire de son grand-père, un collectionneur d'art, et, d'autre part, permettre au jeune homme de découvrir l'amour. Or, comme il arrive généralement dans les pièces de Geneviève Billette, l'entreprise, qui fabrique des puces 
électroniques, opère précisément par l'élimination de toute donnée affective ou artistique: les tableaux du grand-père ont été enfouis dans un caveau et tous les livres ont été éliminés. À Nils, Sacha prédit: "Nils, écoute, sous mes pieds, rugir les splendeurs... Les fresques, les harmonies, les verbes... Toutes les œuvres d'art qui, jadis, éclairaient la tour grondent encore d'avoir été enterrées vivantes. [...] Les œuvres fracasseront la porte de leur prison! Elles grimperont dans la tour, en une tempête de lumière! L'amour brillera à tue-tête!" (p. 10) On comprend que Sacha prépare sa vengeance et que Nils sera l'instrument de la "révolution sensuelle" ainsi fomentée (p. 21). Chacun à son tour apprendra en effet à "goûter" qui un souvenir, qui une émotion, qui l'amour. Il arrive ainsi que le passeur soit aussi un révélateur, et que les personnages craignent la résurgence de la mémoire qui, comme toute anamnèse, aurait pour résultat de transformer la vie. Finalement, il faudra congédier Nils qui génère, précisément, "trop de vie" (p. 100), car "l'entreprise n'y résisterait pas" (p. 101).

$$
\text { *** }
$$

Dévoilement devant notaire ${ }^{9}$ de Dominick Parenteau-Lebeuf propose aussi un modèle où le passage du récit se réalise d'une génération à l'autre. La pièce a remporté la Prime à la création du Fonds Gratien-Gélinas et elle a été créée le 22 octobre 2002 au Théâtre d'Aujourd'hui, dans une mise en scène de Marc Béland. Il n'y a pas ici d'anamnèse au sens strict, puisque la transmission opère à travers un testament et un héritage.
Aussi est-ce le notaire qui joue le rôle du passeur. La pièce se présente comme une suite de tableaux titrés, comme autant de chapitres du manuel de survie ou comme autant de documents produits par la Chambre des Notaires et que consulterait une femme qui vient d'enterrer sa mère féministe, morte d'un cancer du sein. Les personnages se retrouvent après l'enterrement: Irène-Iris, son petit frère Ulysse et le notaire Clinton Haasgard. La pièce porte sur l'angoisse de cet héritage que la fille doit assumer; elle qui a l'habitude de saigner du nez dès que survient un obstacle dans sa vie, "le sang de ta défaillance", dira son frère (p. 23). Elle doit assumer le fait de devenir la première de sa génération. "[O]n se retrouve comme moi, le jour de l'enterrement de sa mère, à se demander: qu'est-ce qui est féminin au juste? Être féministe est-il féminin? Le féminin est-il une maladie de laquelle il faut guérir?" (p. 25) On le voit, l'héritage et l'hérédité se confondent, brouillant la réflexion d'Inès, jusqu'à ce que, finalement, l'héritage soit révélé. Le testament laisse les lampes à Ulysse: "S'il se trouve quelqu'un avec moi au plus profond de cette dernière nuit, je sais que ce sera toi." (p. 57) Irène-Iris hérite de la bibliothèque, composée de contes de fées et des classiques du féminisme contemporain: "Fais-en un autodafé si tu veux, mais n'oublie pas que ces auteures sont aussi tes mères. Que ça te plaise ou non." (p. 57)

$$
\text { ** }
$$

Curieuse pièce enfin que Le testament du couturier ${ }^{10}$ de Michel Ouellette, dont une première version 
a été lue au Café Comid'art à Ottawa le 27 mars 1997, et une seconde créée à la Nouvelle Scène d'Ottawa, sous la direction de Geneviève Pineault, avant d'être reprise par le Théâtre de la Catapulte à la Nouvelle Scène d'Ottawa le 19 février 2003, dans une mise en scène de Joël Beddows. Car la pièce met en scène cinq personnages, mais elle est écrite pour un seul acteur, ce qui lui confère une structure singulière, où les diverses scènes sont conçues comme autant de dialogues où l'interlocuteur n'est que suggéré. Aussi l'anecdote ne se déploie-t-elle que par petites touches, à travers les aveux des uns ou des autres. Flibotte, un commerçant, passe en contrebande un tissu fait de main d'homme et un patron de robe datant du XVII ${ }^{\mathrm{e}}$ siècle, provenant de la Cité, et qu'il offre à Mouton, le couturier de la Banlieue. Nous sommes dans un univers aseptisé où ce genre de chose est interdit. En effet, depuis un certain nombre d'années, une frontière étanche sépare la Cité et la Banlieue pour protéger les habitants de toute contamination physique, intellectuelle ou morale. Même le désir érotique a été éradiqué comme une maladie. Seules quelques femmes en souffrent encore et, telles Miranda, celles-ci suivent une thérapie. Les déviants sont internés par les Services Sanitaires à Lazarette, une sorte de ghetto, aux marges de la Banlieue. Mais voici que le système de contrôle de la frontière a été saboté. Royal, qui attend son investiture à la mairie de la Banlieue, embauche Flibotte pour le réparer.

Pendant ce temps, Mouton, le couturier, a découvert dans le patron un texte manuscrit, de la main d'un couturier, qui lègue le patron de la robe à la postérité, espérant que quelqu'un parviendra à achever le vêtement qu'il n'a pu compléter, son travail ayant été interrompu par la maladie puis par la mort. "Tu dois réaliser les dernières volontés de cet homme mort il y a des siècles" (p. 49), confirme Flibotte. Mais Mouton est malade et il sent qu'il n'a plus beaucoup de temps, car il a compris du Testament que le couturier avait été malade de la peste, maladie qu'il avait lui-même répandue dans la ville d'Eyam pour se venger du pasteur, dont il aimait la fille, mais qui l'avait éconduit. À travers les siècles, le tissu est resté imprégné du virus et il envahit maintenant la Banlieue. La vengeance de Flibotte sera complète, ayant répandu un premier virus dans le système informatique qui contrôle la frontière et en ayant répandu un second dans l'univers biologique. Il a toutefois découvert, sous son propre virus informatique, un second virus, encore plus virulent, implanté par Miranda qu'il engage désormais à fuir, car "[c]'est bien connu, quand le chaos s'installe chez des gens civilisés les pires horreurs sont perpétrées" (p. 89). L'anamnèse, incarnée ici dans le virus de la peste livré par le testament du couturier, va, comme il se doit, contribuer à transformer le présent et ainsi permettre à la vie de se renouveler, mais elle aura d'abord fait table rase de l'Histoire.

1. Jean-Pierre Ryngaert, Lire le théâtre contemporain, Paris, Dunod, coll. "Lettres supérieures", 1993 , p. 69

2. Carole Fréchette, Les quatre morts de Marie, Montréal, Les Herbes rouges, 1995, 116 p.; La peau d'Élisa, Montréal/Arles, Leméac/ Actes Sud, coll. "Papiers", 1998, 32 p.; Les sept jours de Simon Labrosse. Si sa vie vous intéresse, Montréal/Arles, Leméac/Actes Sud, coll. "Papiers ", 1999, 62 p. 
3. Id., Violette sur la terre, Montréal/Arles, Leméac/Actes Sud, coll. "Papiers", 2002, $65 \mathrm{p}$.

4. Id., Le collier d'Hélène, Carnières, Lansman éditeur, coll. "Théâtre à l'affiche", n 2, 2002, $44 \mathrm{p}$.

5. Id., Jean et Béatrice, Montréal/Arles, Leméac/ Actes Sud, coll. "Papiers", 2002, 71 p.

6. Wajdi Mouawad, Rêves, Montréal/Arles, Leméac/Actes Sud, coll. "Papiers", 2002, $66 \mathrm{p}$.
7. Myriam Houle et Marie-José Normand, Les soifs du désert, Montréal, Lanctôt éditeur, 2001, 124 p.

8. Geneviève Billette, Le goûteur, Montréal, Leméac, coll. "Théâtre", 2002, 103 p.

9. Dominick Parenteau-Lebeuf, Dévoilement devant notaire, Carnières, Lansman éditeur, coll. "Nocturnes théâtre, no 119", 2002, 58 p.

10. Michel Ouellette, Le testament du couturier, Ottawa, Le Nordir, coll. "Rappels", 2002, $92 \mathrm{p}$.

\section{Féminismes}

\section{Telles mères, telles filles?}

\section{Lucie Joubert, Université d’Ottawa}

On a souvent constaté que les Américaines et les Canadiennes anglaises se penchent beaucoup plus volontiers sur la littérature québécoise que la critique féministe québécoise ne s'intéresse aux ouvrages de ses voisines de l'ouest et du sud. On n'a qu'à penser aux travaux de Karen Gould, de Mary Jean Green ou de Louise Forsyth, entre bien d'autres, pour prendre la mesure de cette nonréciprocité. Si les raisons d'un tel déséquilibre entre les littératures restent encore à déterminer, deux récents essais viennent encore renforcer cette tendance en proposant des lectures de textes québécois féministes et fondateurs mis en relation avec la littérature française et canadienne-anglaise.

Miléna Santoro ${ }^{1}$, d'abord, signe un essai intéressant dont le titre polysémique ramènera une certaine génération au groupe musical de Frank Zappa (parions que le musicien, célèbre pour ses compositions écla- tées, ne renierait pas l'audace et le non-conformisme des textes à l'étude!) ou évoquera aussi bien la maxime "la nécessité est la mère de l'invention", qui s'applique avec une acuité certaine dans le cas des femmes en quête d'un langage neuf qui leur permettrait de dire leur différence.

L'auteure s'attarde plus particulièrement à des œuvres-phares qui ont jalonné l'histoire du féminisme littéraire: $L a$, d'Hélène Cixous, Lueur de Madeleine Gagnon, L'amèr de Nicole Brossard et Les prunes de Cythère, Mère la mort et La meurtritude de Jeanne Hyvrard. Les auteures constituent, selon Santoro, quatre exemples de mères, dans le sens le plus métaphorique du terme, c'està-dire des écrivaines qui ont donné naissance, si l'on peut dire, à la conscience nouvelle d'un acte d'écrire désormais au féminin. Regroupées en principe pour mettre en relief une communauté de pensée et une 